\title{
The challenge to providing stroke care and rehabilitation in Malawi
}

\author{
George L Chimatiro ', Anthea J Rhoda ${ }^{1}$ \\ 1 University of the Western Cape, South Africa \\ Keywords: global health \\ https://doi.org/10.29392/joghr.3.e2019049
}

\section{Journal of Global Health Reports}

Vol. 3, 2019

\begin{abstract}
Background
Much research activity throughout the world has advanced on acute stroke care interventions, however, patients in low- and middle-income countries (LMICs) benefit less from stroke care practices due to continuing challenges. The aim of this study was to systematically explore stroke care provision challenges at the largest referral hospital in Malawi, from the perspectives of service providers, patients with stroke and their caregivers.
\end{abstract}

\section{Methods \\ A qualitative exploratory study with purposefully-selected participants explored challenges to stroke care from the perspectives of service providers, patients with stroke, and caregivers through focus-group discussions. Semi structured interviews were also conducted with physicians for patients with stroke. Thematic analysis was used to categorize the data.}

\section{Results}

Four key themes emerged: 1) lack of effective implementation of stroke care approaches due to lack of recognition and priority in critical care medicine, limited interprofessional contacts, communication disarray among providers, and lack of follow-up after discharge, particularly from rehabilitation professionals; 2) erratic and insufficient physiotherapy treatment due to limited referrals by physicians, limited visibility of physiotherapists in the hospital, and lack of proper service planning by physiotherapists; 3) Patient-mix challenges from intermingling patients with varying conditions, risking both physical harm and the development of nosocomial infections, and; 4) resource limitations from inadequate qualified service providers, limited medical supplies, unreliable equipment, and lack of warm bedding for patients.

\section{Conclusions}

This study presented the challenges to stroke care provision, from structural, practice, and resource perspectives. There is a need to put in place context specific, and implementable care protocols to facilitate holistic care for patients with stroke. Economically possible structural needs for instance introduction of stroke-specific care wards in the referral hospitals could improve quality of stroke care services in Malawi.

There is a large burden and mortality of stroke all over the world, with the 2013 Global Burden Disease report showing a significant increase in stroke burden over the last two and half decades, ${ }^{1}$ especially in developing countries. ${ }^{1,2}$ In Malawi, stroke is the fourth leading cause of death after HIV/AIDS, upper respiratory tract infections, and malaria. ${ }^{3}$

Management of stroke is therefore, an area of increasing interest even in low to middle income countries, in line with the WHO observation that the stroke burden in the low- and middle-income countries (LMICs) can be lessened by the provision of quality and standardized stroke care. ${ }^{4}$ However, stroke care, particularly in LMICs is hampered significantly by structural and resource challenges. For example, Best Practice Guidelines emphasize that patients with suspected stroke should be admitted to a stroke unit or to generic ward that is specifically staffed by a coordinated inter-professional team with special expertise in stroke care. ${ }^{5}$ In practice, interprofessional care in Africa remains quite limited. Teams exist often in the absence of professional members, such as speech and language therapists and occupational therapists, and are poorly managed. ${ }^{6}$

Resource constraint is another challenge that impedes robust stroke care in LMICs. For example, while some Malawian hospitals run radiological investigations, particularly CT scan and X-ray, this is often in absence of sophisticated diagnostic tools. Therefore, history and physical examination are the strongly-used approaches to diagnosing stroke, ${ }^{7}$ often not specific in differentiating ischemic 
from hemorrhagic stroke. Additionally, it is known that for the best outcome post stroke, physiotherapy should commence within 24 to 48 hours of stroke onset and continue throughout admission period to discharge and community living depending on need. ${ }^{5,8}$ However, physiotherapy services to the Malawian population is not currently adequate due to the general shortage of rehabilitation personnel in the country and lack of recognition of its critical importance in patient management. ${ }^{9}$ Rehabilitation staff shortage is widespread challenge in LMICs, preventing most patients from receiving rehabilitation during their hospital stay, ${ }^{10,11}$ or receiving inadequate rehabilitative care in quality, number of sessions, ${ }^{12}$ and therapy duration. ${ }^{13}$

Contextually, stroke care is also challenged by the absence of direct health policy support from the state or national level. ${ }^{14}$ This is further evident by health priorities, resources focusing on confronting infectious diseases such as HIV, malaria, and tuberculosis ${ }^{15}$; poverty and populations too large to manage ${ }^{2}$; and lack of awareness and understanding of non-communicable diseases in general and stroke in particular, by the general population, healthcare providers, and governments. ${ }^{16}$

To the knowledge of the researchers, there is paucity of research that has explored the challenges to stroke care in Malawi. However, it is clear, patients with stroke have poor outcomes at discharge, ${ }^{17}$ and they experience significant barriers to community reintegration after discharge. ${ }^{18,19}$ Understanding all of these challenges could potentially inform a new model of care for future consideration.

\section{METHODS}

\section{DESIGN, SETTING AND PARTICIPANTS}

A qualitative exploratory approach was used to better understand care practice for patients with stroke at a major referral hospital in Malawi. The importance of qualitative research to successfully translate best scientific evidence into clinical practice is well known. ${ }^{20}$ Malawi is located in southeast Africa, bordered by Zambia to the northwest, Tanzania to the northeast, and Mozambique on the east, south and west. Malawi is over $118,000 \mathrm{~km}^{2}$ with an estimated population of 18 million. The economy is largely based on agriculture which constitutes $90 \%$ of export earnings (Malawi Growth and Development Strategy 2006 -2011). Malawi has a low investment in health with WHO (2008) estimating per capita expenditures at 20 dollars (US). Malawian health service delivery system is four-tiered consisting of community, primary, secondary and tertiary care levels. According to Greenhalgh, et al, ${ }^{20}$ at the community level, the health care service is provided through personnel with basic knowledge in health care called "health surveillance assistants." Health care focus at the community level is preventive interventions. Primary care is delivered through clinics and health centers. Secondary and tertiary care services are provided by district and central (referral) hospitals respectively. The country has 28 district and four referral hospitals across the country. Those four referral hospitals also operate as district hospitals, as there are no distinct districts hospitals in the areas of their location.
This research was conducted at Queen Elizabeth Central hospital (QECH) in Blantyre, situated in the southern region of Malawi. QECH, with-1400 bed-capacity is the largest referral hospital in Malawi, and was chosen for convenience. As the largest, it is considered representative of stroke care in the country. Participants were drawn from a group of stroke care service providers that included physicians, rehabilitation personnel, and nurses (Table 1). Due to failed attempts to have physicians in a focus group discussion (FGD) setting, semi-structured open-ended-question interviews were conducted instead, in offices at their workplace to gain their perspectives on stroke care. This approach afforded some flexibility with which the participants could be reached. Two other FGDs were held with patients with stroke and their caregivers (Table 2). The study was conducted in from October to November, 2016.

\section{SAMPLING, SAMPLE SIZE}

Participants in the FGDs were purposively sampled, aiming to have between 6 and 12 participants per FGD. The four FGDs, were comprised of 5 nurses, 5 physiotherapists/rehabilitation technicians, 6 patients with stroke, and 7 informal caregivers. Four semi structured interviews were conducted stroke care physicians. The composition of the first two FGDs were slightly below recommendation by Kuzel, who said, "six to eight participants are enough for homogenous sample” in a qualitative study. However, the number of FGDs in this study is in line with recommendations that indicate FDGs per study must be more than one but seldom more than four. ${ }^{21}$ Eligibility for participation for the service providers' FGD included: providing care to the patients with stroke; serving as a physician in medical department, a rehabilitation member of staff who is a physiotherapist or a rehabilitation technician, or a nurse with a minimum of one year-working with patients with stroke. Patients with stroke or serving as their caregiver was the main criteria for their inclusion in the FGDs. All participants were $\geqslant 18$ years and gave appropriate consent for participation per the College of Medicine Research and Ethics Committee (COMREC) requirements.

Open-ended questions in the local language (Chichewa) were used to guide the FGDs of patients and caregivers, and English version among the professionals. The key issues were the challenges in service delivery and solutions for improving it.

\section{DATA ANALYSIS}

The four FGDs lasted for average of two hours each and the four semi-structured interviews among the physicians lasted an average of 25 minutes each. Data were captured using digital audio recorders. Field summaries developed by the research assistants provided quick impressions of emerging issues and helped researchers to determine information saturation. Recorded data were translated and transcribed verbatim, removing any personal identifiers. Thematic analysis was used to identify, analyse, and report patterns (themes) within data to interpret various aspects of the current research topic. ${ }^{22}$ The primary data was manually analyzed. 
Table 1. Socio-demographic data for service providers

\begin{tabular}{|c|c|c|c|c|}
\hline Profession & Age & Gender & Experience in the current job (years) & Experience in health care (years) \\
\hline \multicolumn{5}{|l|}{ FGD 3 (nursing) } \\
\hline Nurse & 27 & M & $3-5$ & $3-5$ \\
\hline Nurse & 32 & $\mathrm{~F}$ & $6-10$ & $6-10$ \\
\hline Nurse & 23 & $\mathrm{~F}$ & $3-5$ & $3-5$ \\
\hline Nurse & 36 & $\mathrm{~F}$ & $6-10$ & $6-10$ \\
\hline Nurse & 31 & M & $3-5$ & $3-5$ \\
\hline \multicolumn{5}{|l|}{ FGD 4 (rehabilitation) } \\
\hline Physiotherapist & 25 & $\mathrm{~F}$ & $1-2$ & $3-5$ \\
\hline Rehabilitation technician & 32 & $\mathrm{~F}$ & $6-10$ & $6-10$ \\
\hline Rehabilitation technician & 35 & $\mathrm{~F}$ & $6-10$ & $>11$ \\
\hline Physiotherapist & 25 & $\mathrm{~F}$ & $1-2$ & $1-2$ \\
\hline Physiotherapist & 24 & $\mathrm{~F}$ & $1-2$ & $2-5$ \\
\hline \multicolumn{5}{|c|}{ Individualized SSI (medical doctors) } \\
\hline MD consultant 1 & 30 & M & $6-10$ & $6-10$ \\
\hline MD registrar 2 & 27 & M & $6-10$ & $6-10$ \\
\hline MD registrar 3 & 30 & M & $3-5$ & $6-10$ \\
\hline MD consultant 4 & 34 & $\mathrm{~F}$ & $6-10$ & $6-10$ \\
\hline
\end{tabular}

$\mathrm{M}$ - male, F - female, FDD - focus group discussion, MD - medical doctors, SSI - semi-structured interviews

Table 2. Socio-demographics for patients with stroke and her/his caregiver

\begin{tabular}{|c|c|c|c|c|c|}
\hline Initial & Age & Gender & Pre-morbid occupation & Marital status & Relationship to patient \\
\hline \multicolumn{6}{|c|}{ FGD 1 (patients)* } \\
\hline Participant 1 & 39 & $\mathrm{~F}$ & Business woman & Married & - \\
\hline Participant 2 & 64 & $\mathrm{~F}$ & Farmer & Widowed & - \\
\hline Participant 3 & 62 & $M$ & Painter & Married & - \\
\hline Participant 4 & 30 & $\mathrm{~F}$ & Business woman & Married & - \\
\hline Participant 5 & 45 & $\mathrm{~F}$ & Business woman & Married & - \\
\hline Participant 6 & 68 & $M$ & Security guard & Widowed & - \\
\hline \multicolumn{6}{|c|}{ FGD 2 (caregivers) } \\
\hline Participant 7 & 61 & $M$ & Farmer & Married & Brother \\
\hline Participant 8 & 40 & $\mathrm{~F}$ & Business woman & Married & Daughter \\
\hline Participant 9 & 42 & $\mathrm{~F}$ & Business woman & Married & Sister \\
\hline Participant 10 & 20 & $\mathrm{~F}$ & Business woman & Single & Sister \\
\hline Participant 11 & 56 & $\mathrm{~F}$ & Farmer & Married & Spouse \\
\hline Participant 12 & 30 & $\mathrm{~F}$ & Business woman & Married & Sister \\
\hline Participant 13 & 34 & $\mathrm{~F}$ & Business woman & Married & Sister \\
\hline
\end{tabular}

FGD - focus group discussion, $\mathrm{F}$ - female, $\mathrm{M}$ - male *Research participant.

\section{ETHICAL CONSIDERATIONS}

The study was approved by the University of the Western Cape (registration number $15 / 6 / 31$; COMREC of the University of Malawi: approval number P.10/15/1819). All participants either gave written informed consent in in English or the local language or witnessed consent plus thumb-print if illiterate before participation depending on their literacy level. An independent witness, usually a person nominated by the participant or a health worker, read and helped the participants understand the study information before giving. Participants were identified with a number during the FGDs, semi-structured interviews, and data analysis to uphold anonymity.

\section{RESULTS}

The aim of the current study was to explore the challenges related to stroke care practice at a large Malawian referral 
hospital. Data was captured through four FGDs and four semi structured interviews. These reported results are the combined pooled data. Refer participant demographics for participants (Table 1 and Table 2).

Four overall themes emerged from the data. These are 1) Lack of effective implementation of stroke care approaches 2) Erratic physiotherapy treatment 3) Patient-mix challenges and 4) Resource limitation.

\section{LACK OF EFFECTIVE IMPLEMENTATION OF STROKE CARE APPROACHES}

Under this theme, four sub-themes emerged: stroke care lacks recognition in critical care medicine, limited interprofessional contacts, communication disarray, and lack of follow-up after discharge

\section{STROKE CARE LACKS RECOGNITION IN CRITICAL CARE MEDICINE}

Physicians in this study observed that stroke care at the QECH is faced with a clear challenge of recognition in critical care medicine, which in practice places priority on patients who with reversible conditions, such as post-surgery complications. This observation is evident in the quote by a respondent physician 2, “...and the other thing may be our intensive critical care medicine it doesn't allow for, sort of patients who have a lot of comorbidities priority is place on people who have got reversible conditions which are mostly surgical patients. Ah so it's quite difficult to get a stroke patient to ICU. So, in terms of intensive care support, imaging and that kind of stuff we have got several limitations". In addition, there is no dedicated stroke unit and team that is specific to stroke care. This was highlighted by physician 3, "We don't have a dedicated unit for stroke; that is also another challenge".

\section{LIMITED INTER-PROFESSIONAL CONTACTS}

In this study, the service providers, particularly physicians and physiotherapists highlighted the wanting inter-professional contact in the central hospital. They said, apart from sectional handover meetings, professionals of different background do not meet to discuss patient care, as indicated by physician 1: "most people will attend department specific meetings ...so as clinicians we do have meetings but they do not involve nurses, radiologists or physiotherapists". This is supported by what was said by physician 3, "The meetings that we have are mostly the handover meeting. But there is no I should say there is no special meeting for stroke patients". Attempts made in conducting meetings by several professionals before have not been appreciated by others who felt left out of the deliberations. For example physiotherapists think the meeting if chaired by medical department then it will all be medicine, no incorporation of other professions as said by physiotherapist 3: "but then when you go to the morning meetings you find that everything that's being discussed is medicine related and no physiotherapy, it will just be like the patient will require physiotherapy and that it will be as though they don't regard that there is a physiotherapist present so I think over time you get demoralized and stop attending the meetings". This limited inter-professional contact at the hospital level led to difficulty coordinating stroke care services and consequently, poor stroke care at hospital level, as hinted by physician 4: "The care is generally very poor. Ah, especially trying to coordinate to get everyone involved, to get physiotherapy involved. Ah to get good nursing care for the stroke patients I think that's a problem".

\section{COMMUNICATION DISARRAY}

This study revealed that there is inadequate patient advice and education on her/his health condition; limited access to information by caregivers; limited communication of information about diagnosis to the patient and guardian; and lack of privacy related to patient information.

Caregivers described inadequate patient advice and education. Physicians do not take time to explain the patient's condition to the caregivers and what to expect, except through informal channels. For example, Caregiver 3 said she only got the information through the patient's file which she, by default, held, "For me to realize that this is stroke, it was the patients file, as we were waiting to go to the ward, I read the patient file that is when I read that they have written that the patient has stroke, they did not explain to us the problem with the patient". Whereas Caregivers 2 and 4 simply said, "For us they did not tell us that it is stroke" and "when we came to the hospital they did not tell us that this is stroke", respectively. The caregivers also said this continues to time of discharge. Particularly, they did not feel they were taught enough about what they can do after discharge, as evident in what caregiver 7 said, "They did not teach us what to do to the patient at home".

Caregivers also observed that physicians are often ready to give out information about HIV status and nothing more, "What the doctors are open to say is the blood drawn for HIV test that they tell the guardian, but the other information you have to search for yourself to find out what is going on". Although they are not satisfied with the way such sensitive information is handled. "There is this lady ... who draws blood for HIV test, when she comes with the results she will just say you are ok, but you or you, let's meet outside and what kind of a picture is she giving to the other guardian who are there?" In support of this observation, Caregiver 3 simply said, patients are often disappointed with this, "So many patients are disappointed with the way this information is given to them".

Physicians agree with the caregiver observations, but they explained that sometimes it is difficult to pass information about diagnosis because of caregiver expectations. This is evident in what physician 1 said, "Most of the time, people want the situation to reverse, which might not happen".

\section{LACK OF FOLLOW-UP ARRANGEMENTS POST DISCHARGE}

Nurses observed that there is no proper follow up to see how patients are doing after discharge as highlighted by nurse 3 , "When they are discharged straight home, I think there is no proper medical personnel to follow them to their home and see how they are doing except if they are given the days to come for checkup". This probably amounts to many unanswered questions by patients after discharge, as hinted by Patient 
1, "The numbness affects the other side where it was not paralyzed that is the only problem that is remaining and because of my ignorance I just assume it's the medication I am taking. Sometimes is the headache, so this might be another problem".

Respondents alluded to the necessity of follow-up arrangements in checking and correcting carry- over programs. Cooperation between patient and caregiver becomes a challenge as patients feel their guardian is "torturing" them, as observed by physiotherapist 5: "Because sometimes the patient would be cooperative to us as rehab or health worker that they have to listen to them, but if they go home, let's do this they say you are torturing me leave me alone". This is supported by physiotherapists who said follow-up would even help in correcting how caregivers carry out physiotherapy home programs: " "Sometimes, it's not the patient who is always complaining; some guardians are really aggressive. Sometimes you just tell the guardian: can you demonstrate..... How you do things at home, just looking at how the guardian has handled the patient's hand or leg, you even scream yourself, please stop!"(*Physiotherapist 2).

\section{ERRATIC PHYSIOTHERAPY TREATMENT}

This study emphasized limitation in physiotherapy service delivery for patients with stroke at the referral hospitals through the three sub-themes: 1 . Limited referrals by the physicians to the physiotherapists; 2) Limited visibility of physiotherapists in the hospital; and 3) Lack of adequate service plans by physiotherapists.

\section{LIMITED REFERRALS BY PHYSICIANS}

Patients with stroke and rehabilitation personnel observed that there are limited referrals to physiotherapy. For example, Patient 3 said she was not advised to have physiotherapy. This is evident in the quote, "They should have told us that? (about) our conditions and advised us that we need to go for physio. They did not inform us". This sentiment was supported by patient 4 who said, "It's true, they just discharged us without informing us that we have to go for physio". However, some patients experienced that they were treated by a physiotherapist, although it was erratic. While others were seen by the physiotherapist four times per week as evident in this quote from Patient 2, "We were going to the physio department for exercises on the leg and arm for four days", others were seen twice as per Patient 3, "They were coming twice per week. They were stretching me", yet others received no physiotherapy treatment per Patient 4, "We didn't do the physios, and they never came".

While recognizing efforts by some physicians to refer patients with stroke, rehabilitation personnel observed that only a handful are referred. This is evident in the quote by respondent physiotherapist 2, "but in case where nobody has gone to check, we tend to have a couple of referrals but then when you compare with the patients that are discharged and those that come for rehabilitation the numbers are different. Those who come for rehabilitation are few and those who go home are many". But some rehabilitation personnel reasons that physicians weigh who is most affected and so can benefit from physiotherapy and other observed that doctor's workload is huge and they miss out on the need to refer the patient for physiotherapy. According to the rehabilitation personnel those who are less affected by stroke are likely to be discharged without referral to physiotherapy compared to those who are severely affected as evident in the quote by rehabilitation technician respondent 4, "I think the doctors will try to weigh to say we have let's say 12 stroke patients on the ward for example they will see I think the ones who have been very affected by the stroke and weigh them against the ones who have been affected less so I think they will refer the ones who have been affected more to Physiotherapy and the feel better to discharge the ones who have minor complications". But respondent physiotherapist 1 reasons on issues of workload, "They know that there is physiotherapy and they know that this patient needs physiotherapy but when they are writing at the discharge form may be they have a lot of workload they may miss out to say the patient should go through physiotherapy".

\section{LIMITED PHYSIOTHERAPIST WARD VISIBILITY}

Although stroke patients and rehabilitation personnel think there is deficit in referral by physicians, the physicians and nurses think otherwise. The physicians observed that it is the physiotherapist who decide to come late even after referral arguing that the patient is not stable enough to be seen by a physiotherapists as evident in this quote by physician 1, "So we have seen cases whereby you are giving a consultation and people (physiotherapists) come and say they are not stable ah contact us when they are stable. Nothing has been done. So it's that kind of situation". On the other hand, the nurses observed that physiotherapists had limited communication with other professionals. This was noted in what Nurse 3 said: "We the nurses and the physiotherapist most of the times the physiotherapist guy just comes and tell us that I have come for this patient and then they go to the patient and they do whatever they will do after that they will just go, like in my experience". And supported by Nurse 2 who said, there is a need for behavioral change, "but there are others as she has already said they just come and do whatever they wanted to do and off they go, so if there can be a behavior change on that I think it could be better for our patients"

\section{ALMOST NON-EXISTENT PHYSIOTHERAPY PLANS OF CARE}

Physicians observed that patients with stroke received a "raw deal" from the physiotherapy department, as the need for physiotherapy is not matched by availability. It appeared to them that there is no good planning for the service. This is evident in what respondent physician 4 said, "They need $a$ lot of rehabilitation but most of the times there is no good plan or good service for that". As a result, there is a lot of stroke complications such as pressure sores and aspiration pneumonia, evident in this quote by Physician 3: "So, in general like in the ward they get a lot of complications like pressure sores and aspiration pneumonia because they don't get turned enough and there is no adequate care for them (I: $\mathrm{mmh}$ ), ya". 


\section{PATIENT-MIX CHALLENGE}

This study showed that the patients and caregivers observed the mixing of patients with different conditions as causing risk to those with stroke: dangers of physical harm from the confused and infections from those with contagious conditions. This is highlighted by Patient 1: "I have seen that our condition is very serious, that we don't move around and they would mix us with mental patients, I was slapped by a mental patient while I was in the hospital". This is supported by caregivers, "I just want to comment, we were at ward $4 \mathrm{~A}$ and some patients come there with mental problems, if possible, can they be given their own side because at times they disturb other patients like the would want to beat a patient or a guardian or even the nurses" caregiver 5 . Nurses and physicians also supported the patient and caregiver observations. The nurse attributed this to lack of space, as noted by Nurse 1: "the space is not enough we end up mixing them with others who have infectious diseases". On the other hand, Physician 3 simply said, "They are mixed with other patients".

\section{HOSPITAL FACILITIES NOT “DISABILITY-FRIENDLY”}

This study found that caregivers encountered challenges when trying to complete caregiving roles in the hospital. Hospital structures and facilities are not accessible to patients with stroke: do not have supportive features in the toilets and bathrooms, hampering their use. From Caregiver 6: "the issue of the toilets and bathrooms. There is no chair for stroke patients so if you let them sit on the floor how would you help the patient to get up". This was supported by Caregiver 1 "It really difficult to make the stroke patient kneel or sit down at the same time to carry them to the wheelchair so the toilet and the bathroom are not user friendly for stroke patients". The challenge with accessibility is not just limited to bathroom and toilet. Caregivers observed that some facilities necessary for stroke care are also difficult to use. In the $\mathrm{X}$-ray department, it is not easy to position the patient for radiological investigations. Per Caregiver 7, "One, at the $x$ ray department they have the same bed like this and a step, for a stroke patient it is very difficult to carry the patient from the wheelchair, to the steps and on the bed. The step was meant for the patient who is able walk and step without any help. It very difficult for put the patient on the $x$-ray bed".

\section{RESOURCE LIMITATION}

Resource limitation has come through strongly in this study in four sub-themes: 1) limited number of qualified service providers; 2) inadequate medical supplies; 3) unreliable equipment: and 4) lack of warm bedding.

\section{LIMITED NUMBER OF QUALIFIED SERVICE PROVIDERS}

The service providers and caregivers observed that among other challenges to patient care are limits in numbers of qualified to meet the special needs of patients with stroke. For example, physicians highlight that staffing has always been a challenge in all the disciplines that directly provide care to patients with stroke. This is evident from Physician 2: "staffing is always a problem. Not only on the physiotherapy aspect but also on the clinical side. There is usually few people anyway to attend to large number of patients that's number one". And supported by Physician 3, stating that the ratio of patients to nurses is "unbelievable," "When the students are not around, it turns to be difficult because (ward) $3 B$ have got most of the times more than 70 patients and there are a few nurses". There were similar observations by rehabilitation personnel and caregivers. For instance, Physiotherapist 2 said there are limited numbers of rehabilitation personnel in the Physiotherapy Department; therefore, they must be allocated wisely, "we don't have enough people in the department to be able to do that so they would rather place those few people in the wards, where it is really important". Caregivers on the other hand observed that sometimes it is the students who seem to increase the number of personnel, but they leave huge gaps when they go. Along this line caregiver 1 said, "Sometimes the nurses might look as if there are so many but most of them are just trainees. At the end, it's just only one nurse who is on duty, especially on weekends. The nurse might be serving a lot of patients at once and it is very overwhelming on one person".

\section{INADEQUATE MEDICAL SUPPLIES}

This study showed that stroke care settings are riddled with widespread shortages of basic medical supplies such as medication, catheters, nasogastric tubes (NGT), BP machines, bedding and pillows. Shortage of medications are also felt by caregivers who have been told to go and buy them as highlighted by Caregiver 7: "But here they just told just that you have been discharged and gave us one tablet and they told us that the other medication is not available, when we asked where can we get the medication for BP, they told us that you have to buy it". Physicians shared the same observation on shortage of medications and diagnostic tests, both hampering care. Noted by Physician 4: "It's also lack of medication and may be not having access to all the tests that you want to do for them, ya". Limitation of some medical supplies explains stroke complications at ward level such as onset of aspiration pneumonia due to lack of NG tubes to support the dependent patients, highlighted by Physician 3: "sometimes a patient can be out of stroke but has aspiration pneumonia can be quite challenging. And sometimes we don't have NGT for feeding so guardians have to go and buy it". In addition, blood pressure machines are in limited supply, thereby, affecting effective monitoring of stroke patients, highlighted by Nurse 2: "sometimes you might have one BP cuff so that patient needs to be checked BP every two hours and you might happen that you have got five patients with that condition, so sometimes it's kind of difficult to monitor them". Rehabilitation personnel see limitation of beddings and pillows as affecting treatment techniques, such as positioning as highlighted by Physiotherapist 3: "The positioning has been tricky because we don't have pillows in the ward and some patients will come with basically one cloth and some patients come with a blanket so we can use that before trying to help with the positioning of the patient but lack of pillows on the ward has also been a challenge". But the shortage of medical supplies is explained by the fact that it is a referral hospital as reasoned by Physician 2, "resources are scarce because ah queens is a big hospital, it's a referral hospital so most of the hospitals refer their patients here and the demand is just too 
high (I: yes). So there are other situations where you may found out that catheters are not even there sometimes in HDU".

\section{UNRELIABLE EQUIPMENT}

The current study found that the other challenge is unreliable equipment mechanically. Diagnostic equipment is often out of working order. Physician 1 said equipment, such as echo-cardiographs are often not able to process, "radiologically yes we just do an echocardiogram because most of the times we are not able to process. We do not have a working CT scan (I: ok), so we can't get an MRI in good time". This was supported by Physician 2, who gave an example of CT scanner not working: "CT scan not at Queens at the moment it was broken down so there is an external arrangement (I: ya) at Adventist. (I: ok, so) A process, anyway, which is not automatic but eventually it works". Frequent breakdown of equipment was also felt by the patients, evident in what Patient 3 said: "they took my book and read it and we went to his office, and he told me that the computer is not working".

\section{LACK OF WARM BEDDING}

Caregivers in this study were concerned that the hospital could not provide warm bedding for the patients, noted by Caregiver 1: "Nowadays, you only have a chitenje (a "wrap"), and you use that to put on the bed and as well as to cover the patient, before they used to give blankets to the patients even when your patient is cold they would bring you extra blankets". This is supported by what caregiver 2 observed as "pathetic," "You are sleeping on plastic mattress, you are covering the patient with a plastic like bed sheet and on top there is a fan, oh it's really pathetic".

\section{DISCUSSION}

The aim of the current study was to explore the challenges to stroke care at a major referral hospital in a low-resource setting. It showed many challenges related to the implementation of stroke care, with little recognition of critical care medicine, limited interprofessional contacts, communication disarray, unavailable or nonoperational equipment, and lack of follow-up after discharge. The finding on lack of recognition of stroke care medicine is interesting but not surprising because in most cases, emergency departments are overcrowded, a direct result of limited ICU beds in most hospitals. ${ }^{23}$ There is a need to power the emergency department through training of relevant health care workers in critical medicine so that most of such critical stroke care is available when the patient arrives at the hospital. This recommendation is in line with what one of the founders of critical care, Dr. Ake Grenvik, wrote in the preface to the Textbook of Critical Care that, many critically ill patients no longer need admission to the hospital if the diagnostic work-up and treatment may be completed in an emergency department. ${ }^{24}$ In a related qualitative study in Ghana among health professionals the authors also found that multidisciplinary stroke team which in most cases is physician-drives was inadequate, not inclusive, and an obstacle to effective patient care. ${ }^{6}$ Additionally, although patients live geographically far away from a hospital, it should put in into its programming follow-up plans specific to patients with stroke. Liaison with district hospitals and health centers can also be critical as patients with stroke as well as their caregivers have a need for long-term care. ${ }^{25}$

This study unearthed limitation in physiotherapy service delivery for patients with stroke at the referral hospitals through three themes: 1) limited referral by the physicians to the physiotherapists; 2) limited visibility of physiotherapists in the hospital: and 3) lack of proper service plans by physiotherapists. In line with a Ghanaian study finding, general nurses believed that the absence of a specific protocol or clinical guideline for acute stroke care was a key barrier. ${ }^{6}$ We reasoned that the protocols set in place would enforce general understanding that different professionals are needed for holistic care for patients with stroke. Additionally, as utilization of physiotherapy during hospital admission has been associated with reduced length of hospital stay among patients with stroke, ${ }^{26}$ there is a need for hospital physicians to recognize and engage physiotherapist as early as possible along stroke care continuum.

The current study further showed that patients with stroke and caregivers observed the mixing of patients with different conditions as increasing the risks to communicable diseases for those with stroke. They observed that the tendency of mixing stroke patient with other conditions such as the confused and those with infectious diseases brings with it a danger of physical harm and infection. This is against common trends in other countries, where admission to a stroke unit is recommended even in developing countries. ${ }^{6}$ In addition to this seemingly structural challenge, this study found that the caregivers observed that hospital structures and facilities are not accessible to patients with stroke. As a step towards better care of patients with stroke, Malawi need to consider instituting stroke units with all facilities in place and accessible. Provision of adequate infrastructure has been associated with the increased level of job satisfaction among health workers and a potential factor for prevention of nosocomial infections. ${ }^{27}$

Resource limitation is another challenge (qualified service providers, inadequate medical supplies, unreliable equipment, and lack of warm bedding). This study echoed the findings in Ghana where limited staff especially stroke specialists, shortage of medical equipment, such as blood pressure (BP) monitoring apparatus, cardio monitors, suction machines, adjustable hospital beds and inadequate space to facilitate patient care, were key barriers across the study sites. ${ }^{6}$ There was a need for hospitals to be competitive through provision of equal opportunities for career advancement, lifelong learning, and flexible work schedules as well as develop policies that promote loyalty and retention $^{28}$ of the few who are already in the system.

\section{LIMITATIONS}

This study was conducted at only one of the four referral hospitals in Malawi, which may have differing presentations in practice and context. However, as the largest referral hospital in the country, there may be higher likelihood of "representativeness" regarding challenges to stroke care in similar-level hospitals. Additionally, this study does provide impetus for further research to quantitatively under- 
stand the challenges on a wider scale of health care deliver in the country.

\section{CONCLUSIONS}

This study presented the challenges in stroke care provision from a pooled data of focus group discussion and semistructured interviews. The challenges are structural, where space and inaccessible structures affects service provision, practice, where there is limited multidisciplinary teamwork and; resource, where there is a handful of qualified service providers, inadequate medical supplies, and unreliable equipment. There is a need to put in place context specific, and implementable care protocols to facilitate holistic care for patients with stroke. The is also a need to promote robust leadership in the referral hospitals whereby individual hospitals, with government support, could work to create equal opportunities for provider career advancement and develop policies that promote stroke-specific care skills, loyalty and retention of the existing workforce. This would, additionally, include attempts to put in place economically possible structural needs for instance introduction of stroke-specific care wards in the referral hospitals.

\section{ACKNOWLEDGEMENTS}

We thank Dr. Leslie Glickman, educational consultant, for her invaluable support during this study especially during questionnaire development and overall manuscript editing;
Liesbet De Wit, PT, PhD, Professor at the Vrije Universiteit Brussels, Department of Public Health, Belgium for the support she rendered during the early stages of this study; Dr. Augustin Choko peer support director and heads of departments for QECH and KRC for accepting implementation of data collection processes; research assistants Dexter Killi for working to making the data collection process a reality. And to the patients, caregivers, families, and staff, my heartfelt thanks for your time, cooperation, insights, and honesty in answering the questions posed by this study. Without all of you, the results of this important research would not have become a reality.

\section{FUNDING}

None.

\section{COMPETING INTERESTS}

The author completed the Unified Competing Interest form at http://www.icmje.org/coi disclosure.pdf (available upon request from the corresponding author), and declare no conflicts of interest.

\section{CORRESPONDENCE TO:}

George Chimatiro, PT, MSc, Medical Rehabilitation College Box 256

Blantyre

Malawi

chimatirogeorge@hotmail.com 


\section{REFERENCES}

1. Feigin V, Forouzan M, Krishnamurthi R, Global Burden of Diseases, Injuries, and Risk Factors Study 2010 (GBD 2010), GBD Stroke Experts Group. Global and regional burden of stroke during 1990-2010: findings from the Global Burden of Disease Study 2010. Lancet. 2014;383:243-254. doi:10.1016/S0140-6 736(13)61953-4

2. Feigin VL, Lawes CMM, Bennett DA, Barker-Collo SL, Parag V. Worldwide stroke incidence and early case fatality reported in 56 population-based studies: a systematic review. Lancet Neurol. 2009;8(4):355-369. doi:10.1016/s1474-4422(09)7002 $\underline{5-0}$

3. Centers for Disease Control and Prevention. National Center for Chronic Disease Prevention and Health Promotion, Division of Population Health, Chronic Disease Indicators (CDI) Data. Published 2016. Accessed January 20, 2018. https://chronicdat a.cdc.gov/Chronic-Disease-Indicators/U-S-Chronic-D isease-Indicators-Cardiovascular-Dise/232j-jiq5

4. World Health Organization. The World Health Organization warns of the rising threat of heart disease and stroke as overweight and obesity rapidly increase. Published 2005. Accessed January 5, 2018. $\underline{\mathrm{h}}$ ttps://www.who.int/mediacentre/news/releases/2005/ pr44/en/

5. The Scottish Intercollegiate Guidelines Network. Management of Patients with Stroke: Rehabilitation, Prevention and Management of Complications, and Discharge Planning. SIGN; 2010. Accessed December 20, 2018. https://www.sign.ac.uk/assets/sign118.pdf

6. Baatiema L, de-Graft Aikins A, Sav A, Mnatzaganian G, Chan CKY, Somerset S. Barriers to evidence-based acute stroke care in Ghana: a qualitative study on the perspectives of stroke care professionals. BMJ Open. 2017;7(4):e015385. doi:10.1 136/bmjopen-2016-015385

7. Mahawish KM, Heikinheimo T. Stroke in Malawi What do we know about it and how should we manage it? Malawi Med J. 2010;22(1):24-28. doi:10.4314/mm j.v22i1.55905

8. Canadian Best Practice Recommendations for Stroke Care. Published online 2013. Accessed November 18, 2018. https://www.strokebestpractice s.ca/-/media/1-stroke-best-practices/resources/profes sional-resouces/csbp-taking-action-resource-overvie w_en_22may13f.ashx

9. Fielder S, Mpezeni S, Benjamin L, Cary I.

Physiotherapy in Malawi-a step in the right direction. Malawi Med J. 2013;25:83-85.
10. Mohd Nordin NA, Aziz NA, Alkaff SE, Sulong S, Aljunid S. Rehabilitation for patients after stroke in a tertiary hospital:is it early and intensive enough? Int J Ther Rehabil. 2012;19(11):603-611. doi:10.12968/ijtr.2 $\underline{012.19 .11 .603}$

11. Urimubenshi G, Rhoda A. a process of physiotherapy services of stroke patients treated at Ruhengeri Hospital in Rwanda:A four-year docuent review. JCHS. 2010;5:26-33.

12. Reuter B, Gumbinger C, Sauer T, et al. Access, timing and frequency of very early stroke rehabilitation - insights from the BadenWuerttemberg stroke registry. BMC Neurol. 2016;16:222. doi:10.1186/s12883-016-0744-7

13. Jette DU, Latham N, Smout R, Gassaway J, Slavin M, Horn S. Physical therapy interventions for patients with stroke in inpatients rehabilitation facilities. Phys Ther. 2005;85:238-248. doi:10.1093/ptj/85.3.238

14. Baatiema L, Otim M, Mnatzaganian G, Aikins ADG, Coombes J, Somerset S. Towards best practice in acute stroke care in Ghana: a survey of hospital services. BMC Health Serv Res. 2017;17:108. doi:10.11 86/s12913-017-2061-2

15. Bonita R, Mendis S, Truelsen T, Bogousslavsky J, Toole J, Yatsu F. The globe stroke initiative. Lancet Neurol. 2004;3:391-33. doi:10.1016/S1474-4422(04)00 $\underline{800-2}$

16. Checkley W, Ghannem H, Irazola V, et al. Management of Noncommunicable disease in lowand middle-income countries. Glob Heart. 2014;9(4):431-443. doi:10.1016/j.gheart.2014.11.003

17. Chimatiro GL, Rhoda A, DeWit L. Stroke patients' outcomes and satisfaction with care at discharge from four referral hospitals in Malawi: A cross-sectional descriptive study in limited resource. Malawi Med J. 2018;30(3):152-158. doi:10.4314/mmj.v30i3.4

18. Glickman LB, Chimatiro G, Neely L, White N, Walters ES, Warres M. Community reintegration of clients post discharge from Kachere Rehabilitation Centre,Malawi. J Glob Health. 2015;4:34-38. doi:10.10 16/i.physio.2015.03.3240

19. Chimatiro G, Rhoda A. Environmental barriers to reintegration experienced by stroke clients post discherge from a rehabilitaion centre in Malawi. South African Journal of Physiotherapy. 2013;70:20-25. 
20. Greenhalgh T, Howick J, Maskrey N. Evidence based medicine: a movement in crisis? BMJ. 2014;348(jun13 4):g3725. doi:10.1136/bmj.g3725

\section{Stewart D, Shamdasani P, Rook D. Focus Groups:} Theory and Practice. SAGE Publications; 2007. doi:10.4 $135 / 9781412991841$

22. Boyatzis RE. Transforming Qualitative Information: Thematic Analysis and Code Development. Sage; 1998.

23. Huang DT. Clinical review: Impact of emergency department care on intensive care unit costs. Crit Care. 2004;8(6):498-502. doi:10.1186/cc2920

24. Grenvik A, Ayres S, Holbrook P, Shoemaker W. Textbook of Critical Care. 4th ed. W.B. Saunders Company; 2000.
25. Visser-Meily JMA, van den Bos GAM, Kappelle LJ. Better acute treatment induces more investments in chronic care for stroke patients. Int J Stroke. 2009;4(5):352-353. doi:10.1111/j.1747-4949.2009.003 19.X

26. Olaleye OA, Lawal ZI. Utilization of physiotherapy in the continuum of stroke care at a tertiary hospital in Ibadan, Nigeria. Afr Health Sci. 2017;17(1):79-87. d oi:10.4314/ahs.v17i1.11

27. Manyisa Z. A conceptual model for improving working conditions in public hospitals in Mpumalanga Province. An occupational health and safety perspective. Published online 2015.

28. Marchal B, Brouwere VD, Kegels G. Viewpoint: HIV/AIDS and the health workforce crisis: What are the next steps? Trop Med Int Health. 2005;10(4):300-304. doi:10.1111/j.1365-3156.2005.01 397.x 